\title{
¿ $\begin{aligned} & \text { ГОСУДАРСТВЕННЫЕ ИНСТИТУТЫ } \\ & \text { И ПРАВОВЫЕ СИСТЕМЫ }\end{aligned}$
}

Радочина Т.Н.

\section{ЧАСТНЫЕ ТЮРЬМЫ В ПЕНИТЕНЦИАРНОЙ СИСТЕМЕ АНГЛИИ И УЭЛЬСА}

Аннотация: История формирования идеи о привлечении услуг частного бизнеса в сферу уголовно- исполнительной деятельности в Великобритании (1980-е г2); создание теоретической, правовой основ частного тюремного сектора, начало эксперимента по коммерческому менеджменту первых тюрем, развитие новых форм коммерческих форм имеханизмов в тюремной системе Англии и Уэльса. В сферу предмета также вошли статистические данные Тюремной системы Англии И Уэльса, официальные справки и документы о деятельности частных тюорем, официальная информация о позитивных и негативных результатах использования частного бизнеса в тюремной системе, дискуссии имнения отдельных известных политических деятелей, ученых и сотрудников юстиции, создающие достаточно полное представление о современном состоянии даннойобласти правоотномений в Англии и Уэльсе. Методология исследования, нарядус общенаучнымиметодами (индукиии, дедукции и др.) включает совокупность традиционных для криминологии и уголовно- исполнительном праве методов и методик, в частности это: исторический и сравнительно- правовой анализ, формально-логический, статистический и динамический, из сочиологических методов был использован метод изучения документов. Научная новизна данной статьи заключается, во-первых, в отражении проблемы применения услуг частного бизнеса в новых современных условиях, включая анализ соответствуюшего 20-летнего опыта Англии и Уэьса. Новизнойобладает отраженная автором самобытность, неповторимость становления иразвития данного института применительно кусловиям Великобритании. Выявленные противоречия и результаты данного опыта такжеявляются новыми, полученнылии из исследованных автором английских научных и офищиальных источников непосредственно в процессе написания статьи. Выводы автора непосредственно касаются возможности ицелесообразности использования частного бизнеса вуголовно-исполнительной системе Российской Федераиии и ориентируют теоретиков, правоведов и практиков на разработку новых проектов по развитию пенитенииарной системы нашей страны.

Abstract: The history of the idea formation of bringing the services of private business to the sphere of penal activities in Great Britain (1980s); creation of the theoretical and legal framework for the private prison sector, the beginning of the experiment on the commercial management of first prisons, the development of new forms of commercial forms and mechanisms in the penal system of England and Wales. The scope of the subject also includes the statistical data relating to the penal system in England and Wales, official certificates and documents about the positive and negative results of using private businesses in the penal system, debates and opinions from well-known political figures, scientists and employees of Justice, thereby creating a fairly complete picture of the current state of this field of legal relations in England and Wales. The methodology of the study, along with the scientific methods (induction, deduction, etc.), includes the whole complex of methods and techniques that have traditionally been used in criminology and criminal law enforcement. In particular, this means a historical and comparative legal analysis, a formal-logical one, a statistical one and a dynamic one; concerning the sociological methods, the method of studying documents was used. The scientific novelty of this article is aimed, first of all, at the reflection of the problem of using the services of the private sector in the new modern conditions, including the analysis of the relevant 20-year experience of England and Wales. The novelty is contained in the identity, reflected by the author, of the originality of formation and development of this institution in relation to the prevailing conditions in Great Britain. The identified contradictions and results of this experiment are also new; they have been received from English scientific and official sources, and have been directly studied by the author in the process of writing the article. The author's conclusions are directly related to the possibility and practicability of using private business in the penal system of the Russian Federation and to encourage theorists, legal scholars and practitioners to develop new projects for the development of the penal system of our country.

Ключевые слова: частные тюрьмы Великобритании, Партия консерваторов, эксперимент, частный тюремный менеджмент, конкуренция, приватизация и деприватизация, дискуссии, статистика, прогнозы, заимствование опьтта Keywords: Private prisons of Great Britain, Conservative Party, experiment, private prison management, competition, privatization and de-privatization, discussions, statistics, forecasts and borrowing experience. 
$\Pi$ ервой стадией в развитии института частного сектора в тюремной системе Великобритании было формирование идеологической платформы. Под влиянием американской теории свободных рыночных отношений, в рамках научных разработок Института Адама Смита (учрежден в 1984 г. в Лондоне) было сформировано теоретическое предположение, что передача государственных функций строительства тюрем и их управления под «крыло» частного бизнеса позволит сократить бюджетные расходы страны на содержание тюремной системы, в частности, путем сокращения количества исправительных учреждений, а также использования коммерческим сектором инновационных технологий в данной сфере деятельности. ${ }^{1}$ Лучшее качество при меньших затратах - суть данной идеи, которая оказалась весьма привлекательной для последующей реализации её в жизнь.

Идея получила поддержку консервативного правительства Маргарет Тэтчер (1979-1990гг), политика которого была ориентирована на внедрение в государственные структуры экономически привлекательных рыночных схем, основанной на позиции, что частный сектор более эффективен и результативен, и здоровая конкуренция между частным и государственным сектором послужит катализатором разностороннего прогресса тюремной системы.

Статистика сферы исполнения уголовных наказаний в Англии и Уэльсе того времени также свидетельствовала о необходимости проведения пенитенциарной реформы.

На фоне постоянного роста объемов государственного финансирования пенитенциарных учреждений и, в то же время, ухудшения условий содержания, резко обозначилась проблема их переполненности: с 1979 по 1988 гг. число осужденных в тюрьмах возросло на $18 \%$, а количество заключенных под стражу - почти вдвое. К тому же многие тюремные здания были построены еще в викторианскую эпоху и условия отбывания в них наказания не соответствовали приемлемым стандартам содержания лиц, лишенных свободы. Таким образом, необходимость серьезных реформ в тюремной системе мало у кого из представителей прогрессивной общественности вызывала сомнения.

Вместе с тем, с момента зарождения института частного тюремного сектора сама данная идея, а впоследствии и сама практика использования услуг частного бизнеса в пенитенциарной системе всегда подверга-

${ }^{1}$ См., например: Privatizing Prisons: moral case, by Professor Charles H Logan.26 Nov.1987. ASI (Reseach), LTD. London SWIP P 2. лись острой критике. Так, британская политическая оппозиция отмечала, что тэтчеристы в своем стремлении приватизировать все, и даже тюрьмы, фактически повторяют стремление левых социалистов обратить всю частную индустрию в государственный сектор. Иные критики утверждали, что создание системы частных тюрем скорее популистский политический шаг, нежели заимствование сомнительно лучшего практического опыта, сделанный под влиянием американской теории свободного рынка, тем более что данный опыт еще не получил надежного обоснования.

Тем не менее, идеологическое «зерно упало на благодатную почву» и сегодня мы должны констатировать уже достаточно большой опыт функционирования института частного тюремного бизнеса в пенитенциарной системе Великобритании, поскольку он существует уже более 20 лет.

Историческое развитие института частного сектора в тюремной системе Великобритании можно условно подразделить на четыре периода:

- 1981- 1991 гг. - формирование идеи и ее обоснование ;

- 1992- 1997 гг. -открытие первых управляемых по коммерческим контрактам тюрем, становление и развитие конкуренции между частным и государственным сектором в пенитенциарной системе;

- 1998- 2010 гг. - возвратно- поступательное развитие института приватизации тюрем, обострение конкуренции, обобщение опыта применения частного менеджмента в тюремной системе;

- с 2011г. по настоящее время - начало приватизации тюрем, работающих на «конечный результат»; ужесточение государственного контроля за частным бизнесом в тюремной системе.

Обращаясь к первому этапу становления рассматриваемого института, следует отметить, что в 1986 году специальной комиссией Министерства внутренних дел Англии и Уэльса было обстоятельно исследовано положение дел в тюрьмах и параллельно с этим изучен прогрессивный пенитенциарный опыт отдельных стран на предмет его возможной имплементации в местную практику. В частности, представители комиссии посетили некоторые исправительные учреждения США, управляемые частными компаниями (Corrections Corporation of America (CCA) и Radio Corporation of America).

По итогам поездки, в 1987 году членами комиссии был подготовлен доклад «Контрактное обеспечение тюрем», в котором сделан вывод, что очевидными плюсами управления тюрьмами на основе контрактов 
DOI: $10.7256 / 1811-9018.2014 .1 .10615$

При цитировании этой статьи сноска на доі обязательна

\section{Право и политика 1 (169) 2014}

с частными компаниями являются освобождение госбюджета от необходимости немедленного выделения средств на капитальное инвестирование в строительство, реконструкцию, ремонт данных учреждений; а также многократное увеличение темпов строительства тюремных зданий при очевидно лучшем качестве. В заключении, комиссией было рекомендовано в порядке эксперимента разрешить частным компаниям строительство и затем управление тюрьмами, предназначенными для содержания заключенных под стражу (аналог российских следственных изоляторов), поскольку, как указывалось в докладе, именно эти учреждения отличаются максимальной переполненностью.

Далее, в течение нескольких лет, на уровне Министерства внутренних дел страны, проходили многочисленные слушания и обсуждения, посвященные анализу и оценке достоинств и недостатков участия частного менеджмента в деятельности учреждений тюремной системы. ${ }^{2}$

В 1990 году правительством была одобрена идея передачи некоторых тюрем под крыло частного бизнеса, но только в отношении тюрем, предназначенных для заключенных под стражу и во вновь построенных зданиях. Билл уголовного правосудия (Criminal Justice Bill) 1990 г. в развитие данной программы наделил министра внутренних дел правом заключать коммерческие контракты подобного рода. Однако вскоре, Акт уголовного правосудия (Criminal Justice Act) 1991 г. расширил границы его полномочий до возможностей заключения данных контрактов с любыми тюрьмами. Один из разделов данного закона «Тюрьмы, управляемые по контрактам», регламентировал основные положения вновь созданного института, в том числе такие, как правовой статус офицеров, разделение функций с государственной Тюремной службой и т.п. ${ }^{3}$

Следует заметить, что данный факт впоследствии неоднократно подвергался острой критике и многими был оценен как поспешный шаг, поскольку первоначально принятое решение о необходимости анализа и оценки результатов апробации первого шага (привлечения частного сектора к управлению по контрактам только вновь построенными тюрьмами и только для заключенных под стражу) в определенной степени

\footnotetext{
${ }^{2}$ Pozen D. Managing a Correctional Marketplace: Prison Privatisation in the United States and the Unated Kingdom/Journal of Law and Politics. 2003. Vol.XIX. No. 253-282. P.261-262.

${ }^{3}$ Criminal Justice Act 1991. C. 53. Part IV. Section 84//http://hansard. millbankystems.com/lords/1992/jul/07/criminal-justice-act-1991-contracted-out
}

потеряло свой смысл. Так, например, в январе 1992 г. министр тюремной службы Ангела Рамболд заявила, что переход к приватизации тюрем будет следующим шагом, сделанным только после того, как будет доказана эффективность управления частными компаниями следственными изоляторами.

Тем не менее, правовая основа для участия бизнеса в тюремной системе Великобритании была создана.

Первым учреждением, переданным в частное управление по контракту, выигранному европейской компанией «Групп фо» (Group 4) в 1992 году, была только что построенная тюрьма Wolds на 320 мест, предназначенная для содержания заключенных под стражу мужчин. По прошествии года, в 1993 г., в докладе о положении дел в данной тюрьме, были отмечены как позитивные, так и негативные моменты - в частности, речь шла о проблемах обеспечения режима.

На данном этапе становления института частного управления тюрьмами заключались краткосрочные контракты (максимум 5 лет), и правительство оставляло за собой право собственности на здания и сооружения, обеспечивавшие функционирование данных учреждений. Впоследствии, при пролонгации данных контрактов с частными компаниями, их сроки действия составляли уже 10, иногда 15, а потом и 25 лет, однако обязательным условием по истечению их сроков был переход права собственности на здания и управление подконтрактными учреждениями Тюремной службе.

Контракты заключались в соответствии с Программой частной финансовой инициативы - PFI (Private Finance Initiative), разработанной в ноябре 1992 г. правительством консерваторов. Основной целью программы было расширение сферы частного бизнеса в деятельности государственных служб и структур. Важным нововведением становится передача в частный сектор не только управления и обслуживания тюрем, но наряду с этим строительства и дизайна тюремных комплексов. Заинтересованность бизнеса в строительстве пенитенциарных учреждений и их управлении подкреплялась долгосрочными PFI-контрактами на 25 лет.

В закрепление данных программных позиций, были внесены соответствующие изменения в законодательство (Criminal Justice Act, Public Order Act, 1994), которые закрепели возможности привлечения коммерческих компаний не только к управлению тюрьмами, но также и к строительству тюремных зданий и комплексов. Таким образом, с 1994 г. строительство, дизайн, обеспечение осужденных и управление новыми тюрьмами осуществлялось частными компаниями, согласно условиям PFI- контракта, на 25 лет. 
К этому времени частным сектором уже были выиграны два следующих контракта по управлению тюрьмами Блэйкенхарст (Blakenhurst) и Донкастер (Doncaster), оператором которых стала британская UKDS (крупнейшая корпорация UK Detention Services Ltd., фактически сформированная CCA - Corrections Corporation of America, совместно с такими строительными компаниями как $\mathrm{Sir}$ Robert McAlpine\&Sons Ltd. И John Mowlem \& Co).

В 1997 году была открыта первая построенная частной компанией и переданная ей в управление по коммерческому договору тюрьма Алткурс (Altcourse). В том же 1997-м году открылась единственная на протяжении многих лет частная тюрьма Парк (Parc) в Уэльсе.

Идеологическое противостояние в отношении к приватизации тюрем, как уже указывалось, наблюдалось на всех этапах развития данного института. По- видимому, неочевидность стопроцентного успеха первоначального опыта, а также необходимость сделать определенные уступки оппонентам, отстаивающим интересы государственного тюремного сектора в тюремной системе, способствовали тому, что после заключения нескольких частных контрактов Министерство внутренних дел предложило Тюремной службе Англии и Уэльса участвовать в конкурентной борьбе с частными компаниями за заключение новых контрактов. Кен Кларк, министр внутренних дел, тогда отметил, что частные тюрьмы будут стимулировать Тюремную службу к совершенствованию ее деятельности и обеспечивать более интенсивное распространение в государственных учреждениях новейших технологий.

В противовес консерваторам, партия лейбористов заняла позицию неприятия революционной практики приватизации учреждений тюремной системы, отрицая ее рациональную сторону и указывая на недооценку моральных аспектов этого процесса. Так, по мнению многих, не подобает получать прибыль с тюремной изоляции, - это исключительная сфера, в которой коммерции не место, и все тюрьмы, обслуживаемые по коммерческим контрактам, следует передать обратно в государственный сектор. Однако процесс коммерческого менеджмента развивался, и вскоре были подписаны новые частные контракты и пролонгирован действующий, поскольку возвращение частных тюрем в государственный сектор экономически было уже не оправдано, а также, поскольку Тюремной службе было разрешено участвовать в конкурсах на заключение коммерческих контрактов, интересы государственного представительства были учтены.

К 2002 году восемь тюрем страны были переданы в частное управление и работали в основном по 25 -летним контрактам, заключенным с Министерством юстиции. По данным на октябрь 2001 года в Англии и Уэльсе более 6 тыс. заключенных (около 8 \%) содержались в условиях подконтрактных тюрем (к слову, в Шотландии на тот момент 600 человек, что составляло $10 \%$ контингента осужденных, содержались в тюрьмах, управляемых по контрактам). Вместе с тем, к этому времени, как отмечают аналитики, функционирование частного сектора в тюремной системе подверглось определенным объективным изменениям и субъективной переоценке. В частности, две из управляемых частными компаниями тюрьмы были возвращены под «крыло» государственной тюремной системы: в 1999 г. Тюремная служба выиграла конкурс по управлению тюрьмами Бакли Холл (Buckley Hall) и Блэйкенхарст (Blakenhurst), когда сроки ранее заключенных пятилетних коммерческих контрактов истекли. Государственный менеджмент оказался более «дешевым» и, в то же время, обеспечивающий более высокое качество исполнения наказания.

Более того, в 2000 году по итогам маркетингового тестирования, проведенного в государственной тюрьме Манчестер (Manchester), данным учреждением Тюремной службы было продемонстрировано полное соответствие требованиям SLA (service level agreementкритерии деятельности, предусмотренные контрактом), которые не уступали условиям частного контракта, что позволило сохранить учреждение в государственном ведомстве. В случаях, когда государственное учреждение не проходит данного рода тестирование и уровень исполнения наказания признается недопустимо низким, то оно либо подлежит закрытию, либо на право управления им Министерством юстиции объявляется конкурс. В английских источниках отмечается активная роль профсоюзной организации сотрудников пенитенциарной системы (Prison Officer's Association), объединяющей более 35 тысяч человек, и всесторонне поддерживающей государственное администрирование тюремных учреждений.

Нельзя обойти вниманием факт, который отражает исключительно коммерческий интерес частного сектора к участию в тюремном бизнесе (что, разумеется, вполне естественно): так, в 2001 году попытка Минюста отдать в управление частному сектору тюрьму Брикстон (Brixton) провалилась, поскольку данное учреждение находилось в столь плачевном состоянии, что ни одна из компаний не пожелала вложить средства в его «реанимацию», настолько это было экономически убыточно. Показательно, что в эти годы те же процессы наблюдаются и в других странах, имплементировавших в свое законодательство и практику исполнения на- 
DOI: $10.7256 / 1811-9018.2014 .1 .10615$

При цитировании этой статьи сноска на ооі обязательна

\section{Право и политика 1 (169) 2014}

казаний элементы частного тюремного менеджмента, - так, например, в США были расторгнуты несколько частных контрактов и тюрьмы деприватизированы. ${ }^{4}$

На протяжении всего данного десятилетия, дискуссии и острые разногласия по поводу успехов и неудач участия бизнеса в деятельности тюремной системы не прекращались, при этом высказывались самые различные, порой прямо противоположные суждения. Так, Главный тюремный инспектор Англии и Уэльса в те годы, Давид Рамсбозэм (Sir David Ramsbotham), оставаясь на позиции возможного использования частного менеджмента исключительно в отношении управления тюрьмами, предназначенными для содержания обвиняемых, отметил, что государство решает вопрос о наказании - государство должно и исполнять его.

По мнению других аналитиков, строительство тюрем должно быть государственным, а менеджмент может быть и частным.

Третьи ссылались на опыт Франции, использовавшей для исполнения наказания в частных тюрьмах исключительно государственных служащих (смешанная модель). Так, Директором Тюремной службы в 2001 году было замечено, что, вполне возможно, строительство, ремонт тюрем и обслуживание осужденных возможно будет осуществляться по коммерческим контрактам, в то время как управление учреждениями - исключительно государственным сектором. ${ }^{5}$

По мнению отдельных специалистов, можно было бы «отдать на откуп» частному бизнесу абсолютно все функции - начиная со строительства исправительных учреждений и заканчивая организацией процесса ресоциализации после отбывания осужденным лишения свободы. Звучало предложение передать все частные тюрьмы обратно в государственный сектор, а их противники отвечали, что это фактически уже невозможно по финансовым соображениям, учитывая существование многомиллионных долгосрочных контрактов, а кроме того, наработанный в сфере частного тюремного сектора опыт свидетельствует в его пользу, несмотря на отдельные негативные моменты.

\footnotetext{
${ }^{4}$ Cm.: Nossal K, Phillip Wood. The Raggedness of Prisons Privatization: Australia, Britain. Canada and New Zealand and the United States compared. Paper presented for the Prisons 2004 Conference on Prisons and Penal Policy: International Perspectives. City University, London. 23- 24 June 2004. P. 2.

${ }^{5}$ Cm.: Nossal K, Phillip Wood. The Raggedness of Prisons Privatisation: Australia, Britain. Canada and New Zealand and the United States compared. Paper presented for the Prisons 2004 Conference on Prisons and Penal Policy: International Perspectives. City University, London. 23- 24 June 2004. P. 2.
}

Нельзя обойти вниманием достаточно большой объем информации об анализе результатов работы тюрем по контрактам с частными компаниями, сформировавшийся к 2004 -му году. Наиболее часто встречающиеся замечания в отчетах тюремных инспекторов, документах правительственных комиссий, научно- публицистических материалах указывают на такие проблемы приватизационной кампании, как:

- ослабление режима содержания в подконтрактных учреждениях;

- отсутствие предусмотренных контрактом современных инноваций в управлении учреждениями или их недостаточно высокий уровень;

- низкая квалификация сотрудников, сокращение персонала; текучесть кадров (как правило, заработная плата в частных учреждениях на порядок ниже чем в государственных);

- недостаточная занятость осужденных социальнополезной деятельностью;

- отсутствие конкретной статистики, подтверждающей более низкий уровень рецидива по отбытию наказания в частных тюрьмах (как один из основных критериев оценки качества исполнения наказания);

- моральная ущербность практики использования услуг частного бизнеса в тюремном секторе, когда государство способствует получению прибыли частных компаний, что является их самоцелью, используя условия содержания людей в изоляции;

- отсутствие абсолютной подконтрольности и подотчетности управляемых по контрактам учреждений;

- рост тюремного контингента благодаря развивающейся тюремной индустрии и коррупционным связям частных компаний с государственными структурами, косвенной «стимуляции» увеличения сроков лишения свободы и др.

Отдельные специалисты и политики полностью отрицали и отрицают преимущества частного сектора в системе пенитенциарных учреждений. Так, Майк Невалл (Mike Newall), президент ассоциации директоров тюрем, анализируя 10-летний опыт коммерческих контрактов по управлению тюрьмами, в журнале организации написал, что за эти годы частный тюремный сектор в большинстве случаев демонстрирует дорогостоящий сервис, в то время как государственный сектор может обеспечить лучшее качество тюремного менеджмента за меньшие деньги. Он заметил, что проекты оказались столь дорогими, что вряд ли стоит далее развивать систему частных тюрем.

Одна из последних публикаций, подготовленных ассоциацией тюремных офицеров (РОА), отмечает, 
что рынок частного бизнеса в тюремной системе стал одним из высоко секретных, частные компании будут продолжать получать большую прибыль, в том числе, поскольку они функционируют в новых хорошо оборудованных зданиях, в то время как многие государственные учреждения остаются в зданиях викторианской эпохи. В интересах бизнеса, поскольку это его идеология, держать уровень управления государственными тюрьмами настолько низким, насколько это возможно, и, как уже отмечалось, пожалуй, самое главное - в интересах бизнеса обеспечивать максимальную наполняемость тюремных учреждений, что само по себе уже чрезвычайно опасно.

В то же время, нельзя не заметить, что государственные тюремные органы достаточно жестко контролируют деятельность частного сектора в сфере тюремного менеджмента. Так, UKDS была первой частной компанией, оштрафованной в 1994 году на 41, 167 тыс. фунтов стерлингов за утрату контроля над тюрьмой Блэйкенхарст (Blakenhurst). Главным тюремным инспектором было сделано более 100 замечаний и рекомендаций для стабилизации обстановки в данном учреждении, однако это не привело к улучшению ситуации. В 1995 году был осужден к лишению свободы один из офицеров данной тюрьмы за организацию избиения осужденных, несколько сотрудников тюрьмы оказались под подозрением в убийстве чернокожего заключенного; годом позже в данном учреждении заключенный покончил собой. При этом к 1997 году показатели тюрьмы снизились по всем основным критериям: факты насилия среди осужденных составили 14, 1 \% (при стандарте 13, 1\%); время социально-полезной занятости осужденных составило 19, 9 часов в неделю при норме 22,2; оказались выше нормы и результаты тестирования осужденных на предмет употребления наркотиков. В 1998 году управляющая компания была оштрафована вторично на 25 тыс. фунтов стерлингов за побег осужденного. В январе 2001 году правительство объявило, что UKDS проиграла контракт по управлению данным учреждением: услуги компании на $12 \%$ оказались дороже, а их качество на $13 \%$ ниже по сравнению с условиями Тюремной службы. В результате, в августе 2001 года тюрьма была передана обратно в государственное тюремное ведомство.

Следует отметить, что в отдельных сферах функционирования тюрем требования к качеству исполнения наказания в учреждениях, управляемых по частным контрактам, существенно повышены по сравнению с государственными учреждениями данного типа. Так, объем занятости осужденных социально- активной деятельностью в частном учреждении должен составлять 30 часов в неделю, в то время как в государственных- 24. Может оказаться существенной разница и в других составляющих процесса,хотя это не удивительно - подобную картину можно наблюдать и в российской уголовно- исполнительной системе, когда даже субъективно-личностный фактор (опыт, образование, профессиональные и личностные качества сотрудников тюрьмы) в конечном итоге приводит к значительно более высокому качеству исполнения наказания в данном учреждении по сравнению с иными, - например, в сферах применения новых электорнных технологий по обеспечению режима, жилищных условий, питания, медицинского обслуживания, межличностных отношений между администрацией учреждения и лицами, отбывающими наказание.

Показательным оказался опрос населения, организованный изданием Гардиан (Gardian) в марте 2001 г., который отразил отношение общества к передаче частных тюрем обратно в государственный сектор, показав, что 60 \% граждан - за эту меру, 24 \% ответили отрицательно, и $16 \%$ затруднились с выбором ответа. ${ }^{6}$

C образованием NOMS (Национальная служба по надзору за правонарушителями) в 2004 году, под началом которой Тюремная служба со Службой пробации функционируют теперь вместе, после некоторой паузы, процесс побед Тюремной службы в конкурсах за право управления тюрьмами продолжился. Так, в 2005 году государственный сектор успешно выиграл в конкуренции с частными компаниями, отстояв право управления тремя тюрьмами в графстве Кент. В 2013 году известная тюрьма Волдс (Wolds), управляемая компанией Group 4 с 1992 г., будет передана обратно под начало Тюремной службы в результате победы последней в конкурсе за заключение нового контракта.

В марте 2010 г. занимавший пост Министра юстиции Джак Строу объявил о новом виде контрактов по управлению тюрьмами - это договор социального влияния (first social impact bond), заключаемого с такими операторами, как общественные и благотворительные организации, что должно максимально улучшить качество ресоциализации отбывающих наказание, сократить рецидивизм и тем самым укрепить финансирование социального сектора страны путем возвращения в нормальную жизнь после отбывания наказания контингента лиц, успешно прошедших социальную реабилитацию.

\footnotetext{
${ }^{6}$ The Gardian, 21 March 2001.
} 
DOI: $10.7256 / 1811-9018.2014 .1 .10615$

При цитировании этой статьи сноска на доі обязательна

\section{Право и политика 1 (169) 2014}

Сокращение бюджетного финансирования тюремной системы начиная с 2010 года, подтолкнуло правительство к оптимизации процесса приватизации пенитенциарных учреждений, и в апреле 2012 г. тюрьма Бирмингем (Birmingham) стала первым пенитенциарным учреждением, построенным государством, управляемым Тюремной службой, а затем переданным в управление частной компании (Serco). Таким образом, формы и модели развития частно-государственного сотрудничества в тюремной сфере постоянно развивались под влиянием объективных условий и экономической ситуации.

Новая приватизационная политика включала и такой чрезвычайно важный элемент, как оплата по результатам (PbR -payment by results), предполагающий государственное финансирование частных тюрем в процессе исполнения ими наказания только при достижении ими конечной цели, а именно - сокращении рецидивизма как основного критерия качества оказываемых ими услуг. Стоит заметить, что также как и в России, рецидивная преступность в Англии и Уэльсе высокая: по последним данным, почти $60 \%$ осужденных к лишению свободы на срок менее 12 месяцев, по освобождению в течение года вновь совершают преступления.

В 2011 году с дирекцией тюрьмы Донкастер был заключен первый PBR-контракт, включавший подобное условие. В частности, компания Serko, выигравшая контракт, согласно его условиям обязалась ограничить повторное совершение преступлений своими «подопечными» в течение года по их освобождению пятью процентами от общего количества отбывающих наказание, - в случае невыполнения условия штрафные санкции составят $10 \%$ от суммы контракта.

Весной 2012 были открыты построенные коммерческими компаниями тюрьмы Тимсайд (Thimeside) и Оквуд (Oakwood), что свидетельствует о современном развитии первоначального направления приватизационной политики в части продолжания использования капиталов коммерческих компаний в строительстве, на самом первом этапе создания новых тюремных учреждений.

По последним данным, в настоящее время 14 из 141 тюрем Англии и Уэльса являются частными или управляются по контрактам. Из них 10 тюремных комплексов построены частными компаниями и управляются ими согласно PFI- контрактам, три - построены государством и сразу переданы в частное управление, одна - построена государством, функционировала под началом Тюремной службы и затем передана в управление частной компании.
В целом, в данных тюрьмах содержатся около 13500 лиц, что составляет $15 \%$ от общей популяции осужденных и обвиняемых, заключенных под стражу. Две тюрьмы, управляемые под частными контрактами, находятся в Шотландии.

Сфера бизнеса в тюремной системе фактически распределена между тремя основными компаниями операторами - Серко (Serco), Содексо Джастис сервисис (Sodexo Justice services) и Джифоэс (G4S). ${ }^{1}$ По своему масштабу и развитости частный тюремный сектор Великобритании считается вторым после США, - страны, первой реализовавшей идею коммерциализации управления пенитенциарными учреждениями и способствующей имплементации данного института в других странах мирового сообщества.

Что касается политики приватизации тюрем и заключения новых коммерческих контрактов с частным сектором в настоящее время, то можно сказать, что данный процесс продолжается в условиях обостряющейся конкуренции коммерческих компаний и ужесточения контроля государства за качеством тюремных услуг, предоставляемых частным менеджментом. Одним из приоритетных направлений деятельности уголовноисполнительной системы является дальнейшее развитие опыта PBR (оплата по результату). Министерство юстиции Англии и Уэльса постоянно отмечает, что сокращение рецидивизма по-прежнему сотается главной целью работы пенитенциарной системы страны и любого исправительного учреждения, его приоритетным направлением. При этом в данном процессе постоянно появляются все новые идеи и проекты, которые уже внедрены в деятельность тюремной системы, и, несомненно, продолжат свое существование (как, например, первый контракт с участием в качестве инвесторов благотворительных и общественных организаций в тюрьме Питерборо (Peterborough).

В заключении представляется важным отметить весьма существенную терминологическую неточность, часто встречающуюся в отечественных публицистических и даже научных источниках. Речь идет об использовании самого понятия «частные тюрьмы» применительно к институту управления тюрьмами по коммерческим контрактам, о чем шла речь выше. Само понятие «частная тюрьма» в России ассоциируется как правило с частной собственностью, отсюда и представление о полной и абсолютной независимости подобного учреждения от государства, что не соответствует действительности.

Во- первых, тюрьма как публичное учреждение остается по юридической природе государственным 
институтом, и в процессе назначения наказания и распределения заключенных по исправительным учреждениям никакой разницы не существует, - осужденный зачастую не имеет представления, в государственную тюрьму либо управляемую по коммерческому контракту он направлен для отбывания наказания. Уместно заметить, что в некоторых частным образом управляемых тюрьмах условия хуже нежели в средне- статистическом государственном учреждении, это подтверждают и опросы заключенных, и мнения экспертов, и результаты проверок. В то же время, лучшие тюрьмы по качеству содержания осужденных и исполнения наказания также являются частными, каким бы парадоксальным это не казалось. При условии надлежащего отношения к условиям контракта, управляющим коммерческим компаниям удается обеспечить максимально высокий уровень тюремных услуг, который фактически недосягаем для государственных учреждений, учитывая скромное бюджетное финансирование.

Во-вторых, Тюремная служба страны «наполняет» частные учреждения заключенными в соответствии с их лимитом, и тщательно контролирует выполнение требований контракта, в том числе, применяя жесткие санкции за их нарушения. Угроза серьезного штрафа или расторжения контракта по причине невыполнения его условий для коммерческих компаний в данном случае являются очень важными регуляторами надлежащего выполнения условий обязательств по контрактам.

Во-третьих, тюрьма как комплекс зданий и сооружений фактически остается в собственности государства: по истечению срока контракта она передается в ведомство Тюремной службы. Кроме того, возвращение частной тюрьмы в государственный сектор происходит и в случаях грубых нарушений условий контракта, иных, предусмотренных законодательством, обстоятельств, и этот механизм уже запущен.

Остается только сказать, что, несомненно, столь интересный для уголовно- исполнительной системы России опыт, каковым является использование частного бизнеса в тюремной системе Англии и Уэльса, не может остаться незамеченным и вызывает множество дискуссий, в том числе, о перспективах и возможностях внедрения его в нашу отечественную практику. В частности, процесс внедрения частного бизнеса в деятельность пенитенциарной системы вполне можно начать с использования коммерческих услуг лишь в отношении отдельных элементов уголовно- исполнительного процесса, - управления материально-бытовой сферой исправительного учреждения, а также образовательной и производственной.

Заслуживают внимания вопросы привлечения частного бизнеса к строительству, дизайну и ремонту пенитенциарных учреждений. Собственно, идея частногосударственного партнерства в сфере строительства новых следственных изоляторов и тюрем в России уже прозвучала в выступлении Директора ФСИН России Г. А. Корниенко в начале 2013 года. При успешной апробации, уже отработанные схемы функционирования частного сектора в уголовно- исполнительной системе, возможно, будут распространены и на другие сферы деятельности исправительного учреждения, а также при исполнении иных видов уголовных наказаний.

\section{Библиография:}

1. Ch. H. Logan, Privatizing Prisons: moral case, by Professor Charles H Logan.26 Nov.1987. ASI (Reseach), LTD. London SWIP P

2. Pozen D. Managing a Correctional Marketplace: Prison Privatisation in the United States and the Unated Kingdom/Journal of Law and Politics. 2003. Vol.XIX. No. 253-282. P.261-262.

3. Nossal K, Phillip Wood. The Raggedness of Prisons Privatization: Australia, Britain. Canada and New Zealand and the United States compared. Paper presented for the Prisons 2004 Conference on Prisons and Penal Policy: International Perspectives. City University, London. 23-24 June 2004. P. 2.

\section{References (transliteration):}

1. Ch. H. Logan, Privatizing Prisons: moral case, by Professor Charles H Logan.26 Nov.1987. ASI (Reseach), LTD. London SWIP P

2. Pozen D. Managing a Correctional Marketplace: Prison Privatisation in the United States and the Unated Kingdom/Journal of Law and Politics. 2003. Vol.XIX. No. 253-282. P.261-262.

3. Nossal K, Phillip Wood. The Raggedness of Prisons Privatization: Australia, Britain. Canada and New Zealand and the United States compared. Paper presented for the Prisons 2004 Conference on Prisons and Penal Policy: International Perspectives. City University, London. 23-24 June 2004. P. 2. 